\title{
Evolution and variability of Solanum RanGAP2, a cofactor in the incompatible interaction between the resistance protein GPA2 and the Globodera pallida effector Gp-RBP-1
}

Jean Carpentier ${ }^{1,2,3}$, Eric Grenier ${ }^{3}$, Magalie Esquibet ${ }^{3}$, Louis-Philippe Hamel ${ }^{4}$, Peter Moffett ${ }^{4}$, Maria J Manzanares-Dauleux ${ }^{2,5}$ and Marie-Claire Kerlan ${ }^{1 *}$

\begin{abstract}
Background: The Ran GTPase Activating Protein 2 (RanGAP2) was first described as a regulator of mitosis and nucleocytoplasmic trafficking. It was then found to interact with the Coiled-Coil domain of the Rx and GPA2 resistance proteins, which confer resistance to Potato Virus X (PVX) and potato cyst nematode Globodera pallida, respectively. RanGAP2 is thought to mediate recognition of the avirulence protein GP-RBP-1 by GPA2. However, the Gpa2-induced hypersensitive response appears to be relatively weak and Gpa2 is limited in terms of spectrum of efficiency as it is effective against only two nematode populations. While functional and evolutionary analyses of Gp-Rbp-1 and Gpa2 identified key residues in both the resistance and avirulence proteins that are involved in recognition determination, whether variation in RanGAP2 also plays a role in pathogen recognition has not been investigated.
\end{abstract}

Results: We amplified a total of 147 RanGAP2 sequences from 55 accessions belonging to 18 different di-and tetraploid Solanum species from the section Petota. Among the newly identified sequences, 133 haplotypes were obtained and $19.1 \%$ of the nucleotide sites were found to be polymorphic. The observed intra-specific nucleotide diversity ranges from 0.1 to $1.3 \%$. Analysis of the selection pressures acting on RanGAP2 suggests that this gene evolved mainly under purifying selection. Nonetheless, we identified polymorphic positions in the protein sequence at the intra-specific level, which could modulate the activity of RanGAP2. Two polymorphic sites and a three amino-acid deletion in RanGAP2 were found to affect the timing and intensity of the Gpa2-induced hypersensitive response to avirulent GP-RBP-1 variants even though they did not confer any gain of recognition of virulent GP-RBP-1 variants.

Conclusions: Our results highlight how a resistance gene co-factor can manage in terms of evolution both an established role as a cell housekeeping gene and an implication in plant parasite interactions. StRanGAP2 gene appears to evolve under purifying selection. Its variability does not seem to influence the specificity of GPA2 recognition but is able to modulate this activity by enhancing the defence response. It seems therefore that the interaction with the plant resistance protein GPA2 (and/or Rx) rather than with the nematode effector was the major force in the evolution of the RanGAP2 locus in potato. From a mechanistic point of view these results are in accordance with a physical interaction of RanGAP2 with GPA2 and suggest that RBP-1 would rather bind the RanGAP2-GPA2 complex than the RanGAP2 protein alone.

\footnotetext{
* Correspondence: Marie-Claire.Kerlan@rennes.inra.fr

${ }^{1}$ INRA, UMR 1349 IGEPP INRA, Agrocampus Ouest, Université Rennes1,

Ploudaniel, Keraïber F.29260, France

Full list of author information is available at the end of the article
}

\section{Biomed Central}

(c) 2013 Carpentier et al.; licensee BioMed Central Ltd. This is an Open Access article distributed under the terms of the Creative Commons Attribution License (http://creativecommons.org/licenses/by/2.0), which permits unrestricted use, distribution, and reproduction in any medium, provided the original work is properly cited. 


\section{Background}

Wild plant genetic resources are often used in plant breeding strategies to improve various agronomical traits of cultivated plants. Wild plants are continuously evolving to adapt to their changing environmental conditions such as climatic changes, soil quality or pathogens attacks. One consequence of the long evolution of wild species is the diversity observed for some phenotypic characteristics. This diversity is reflected in the genetic variability at the loci controlling the trait. Thus, wild species represent a large pool of valuable diversity that is useful for transferring new agriculturally-important traits, such as pathogen resistance, to crop plants.

Knowledge of the diversity and evolutionary dynamics of genes involved in host-pathogen interactions is needed to generate resistant varieties as well as to prevent pathogens from overcoming resistance. In plantparasite interactions, recognition of pathogen effectors results in the activation of effector triggered immunity (ETI), in which case the effector is often referred to as an avirulence (Avr) protein [1]. Intracellular receptors involved in ETI are usually encoded by resistance $(R)$ genes most of which belong to the nucleotide-binding leucine-rich repeat protein family (NB-LRR) [2]. Many plant-pathogen interactions can be explained by the "gene-for-gene" model in which an $R$ gene provides resistance to the pathogen carrying the corresponding Avr gene $[3,4]$. Avr proteins can activate $\mathrm{R}$ proteins directly or via a cofactor that interacts with the Avr protein [5]. Indirect interactions are often described by the Guard $[4,6]$ or Decoy [7] models. These models predict that $R$ proteins act by monitoring the status of effector targets also known as guardees or decoys. In the absence of the $R$ protein, the targeting of the guardee enhances pathogen virulence whereas the decoy has no impact on virulence or pathogen fitness, but simply resembles the actual virulence target of the effector. While such cofactors appear to play a role in the recognition of the $A v r$ protein $[1,6]$, they likely also function in the proper maturation of the $\mathrm{R}$ protein [5].

Among the identified NB-LRR cofactors, few have been investigated in terms of sequence variability and evolutionary forces shaping their diversity in plant species. The combined analysis of $27 R$ genes and 27 downstream genes in Arabidopsis [8,9] revealed that although $\mathrm{R}$ genes showed hallmarks of balancing selection or partial selective sweeps, most of defence response genes appear to be under purifying selection. The correlation between evolutionary rates and the position at which a gene operates in a pathway has been recently studied using the Pto/Prf signalling pathway in tomato [10]. This pathway involves one NB-LRR gene (Prf), two upstream co-factors (Pto and Fen) and a third co-factor (Rin4) that is predicted to activate downstream defences in tomato, but is also known for its co-factor function in other signalling pathways like the Rpm1 pathway in Arabidopsis [11,12]. Although Pto showed a clear signature of balancing selection, Rin4 showed predominantly purifying selection which tend to suppress the apparition of new variants and $\mathrm{Fen}$ lies between these two genes with signatures of both balancing and purifying selection. More recently, allelic diversity at the locus encoding the RCR3 protein, guarded by $\mathrm{R}$ protein $\mathrm{Cf} 2$ has been shown to be maintained by balancing selection in the wild tomato species Solanum peruvianum. Guardee evolution might be governed by a counterbalance between improved activation in the presence of the corresponding pathogen and prevention of auto-immune responses in its absence [13].

RanGAP proteins were first described as cytoplasmic proteins involved in mitosis and nucleocytoplasmic trafficking [13-15]. The potato RanGAP2 protein has also been described as a co-factor of $\mathrm{R}$ proteins, since it physically interacts, through its WPP domain, with two Solanum tuberosum resistance proteins called $\mathrm{Rx}$ and GPA2 [16]. Rx and GPA2 confer resistance to PVX and potato cyst nematode Globodera pallida, respectively [17] whereas Gpa2 confers resistance to a limited number of G. pallida populations [18]. Compared to Rx, Gpa2 induces a much weaker hypersensitive response (HR) when transiently expressed with its effector counterpart (the avirulence protein Gp-RBP-1 of G. pallida) in tobacco [19]. Unexpectedly, numerous variants of the G. pallida avirulence protein GP-RBP-1 are recognized by GPA2, even those from nematode populations described as virulent against $S$. tuberosum cultivars expressing Gpa2 [20]. Thus, other proteins involved in the recognition of GP-RBP-1 by GPA2 may explain these results and RanGAP2 has been thought to mediate recognition of the avirulence protein GP-RBP-1 by GPA2. Potential for variation in effector recognition due to variation in bait proteins [5] is suggested from studies of the tomato NB-LRR Prf, which recognizes Avr proteins from Pseudomonas syringae through its cofactor, the Pto kinase [21]. Moreover, artificial tethering experiments also suggested that RanGAP2 may facilitate the recognition of Avr proteins via the LRR domains of $\mathrm{Rx}$ and GPA2 [19].

In potato, tobacco and Arabidopsis, two RanGAP proteins (RanGAP1 and RanGAP2) have been described. RanGAP1 binds weakly or not at all to Rx in planta and is therefore probably not important for the function of $\mathrm{Rx} / \mathrm{GPA} 2$ [22]. Although the exact mechanism of recognition of the Avr protein by Rx and GPA2 is still unclear, previous studies have shown that RanGAP2 is required for Rx and GPA2 function [16]. The genetic diversity of the genes encoding both the avirulence proteins (PVX $\mathrm{CP}$ and $\mathrm{Gp}-\mathrm{RBP}-1)$ and the resistance proteins ( $\mathrm{Rx}$ and 
GPA2) has been well characterized. A high frequency of polymorphic sites in the four genes has been identified, including key residues necessary for recognition of the CP and GP-RBP-1 by $\mathrm{Rx}$ and GPA2, respectively $[19,20,23,24]$. On the other hand, the genetic diversity or sequence polymorphism of the co-factor RanGAP2 has not yet been reported. To understand the potential role of potato RanGAP2 in the recognition of Gp-RBP1 by GPA 2 and to eventually identify potato RanGAP2 variants able to enhance or enlarge the spectrum of recognition of Gpa2 towards G. pallida populations, it is necessary to determine the molecular variability and the evolutionary dynamics of this key co-factor.

In this context, the aims of this study were to: i) evaluate the genetic diversity of RanGAP2 in different Solanum species and ii) understand how RanGAP2 variability affects the GPA2-mediated immune response. To this end, we explored RanGAP2 variability in 55 accessions belonging to 18 Solanum species, looking for selective pressure hallmarks and key polymorphic positions in RanGAP2, which could potentially affect either the intensity of the $\mathrm{HR}$ or recognition specificity of Gp-RBP-1 variants by GPA2.

\section{Results}

\section{RanGAP2 structure and variability}

To amplify the RanGAP2 gene from Solanum species we designed primers based on the Solanum RanGAP2 sequence originating from $S$. tuberosum cv Desiree [http://www.ncbi.nlm.nih.gov/nuccore/AM411448]. Comparison of RanGAP1 [http://www.ncbi.nlm.nih.gov/nuccore/ AM411449.1] and RanGAP2 gene sequences from the same cultivar (Desiree) showed that they are only $66 \%$ identical while the RanGAP2 sequences from $S$. tuberosum and Nicotiana benthamiana [http://www.ncbi.nlm.nih.gov/ nuccore/EF396237.1] are 91\% identical, indicating strong conservation of RanGAP2 sequences in the Solanaceae family. We amplified a total of 147 RanGAP2 sequences from 55 accessions belonging to 18 different Solanum species from the section Petota. The maximum number of allelic variants obtained for each genotype corresponded to its ploidy level (two for the diploids and four for the tetraploids), indicating that RanGAP2 is most likely a singlecopy gene in the Solanum genome. BLAST searches against the GenBank/EMBL Databases gave best hits with RanGAP2 (more than 97\% identity with an e-value of 0) and RanGAP1 [AM411449.1] (73\% identity on average with an e-value lower than $10^{-89}$ ), suggesting that, apart from RanGAP1, RanGAP2 does not have any close homologues in potato. All the RanGAP2 sequences obtained lacked introns and had a CDS of 1662 bp (553 amino acids), with the exception of one sequence obtained from accession 78S.248.1 of S. vernei (sequence VRN2-A1). This particular sequence variant has a nine nucleotide in frame deletion (nucleotides 1546 to 1554 corresponding to amino acids 516 to 518). All sequences encoded for a WPP domain at the 5'end (corresponding to amino acids 14 to 109) and 10 LRRs (corresponding to amino acids 213 to 493), a structure identical to that of the RanGAP2 orthologs sequenced in N. tabacum and Arabidopsis thaliana. Polymorphism analysis revealed 318 (19.1\%) polymorphic sites spread over the entire RanGAP2 sequence: 162 singletons and 156 parsimony informative sites. Among these 318 mutations, 47\% are non-synonymous (mutations causing amino acid substitutions). Furthermore, $67 \%$ and $55 \%$ of the singletons and parsimony informative sites, respectively, are nonsynonymous. One hundred and thirty three haplotypes were obtained from the 147 sequences. Haplotypes shared between species: $S$. tuberosum ssp andigena/S. phureja, S. tuberosum ssp tuberosum/S. vernei and S. vernei/S. spegazzinii (Table 1). The pi diversity index of most tetraploid species was higher than that of the diploid species. The exception was the cultivated diploid species S. stenotomum, which showed the highest sequence diversity.

\section{Phylogenetic analyses}

Whatever the method used (maximum likelihood, maximum parsimony or minimum evolution), no clear evidence of phylogenetic structure was observed, as illustrated with the maximum likelihood analysis (Figure 1). Thus sequences from species with the genome formulae AA (diploid) or AAAA (tetraploid) were not structured according to the species origin. Nonetheless sequences derived from the diploid species with the genome formula BB [25] and from the di- and tetraploid species from Mexico and the USA tend to group together.

Findings from the phylogenetic tree were then confirmed with factorial analysis. As can be seen in Figure 2, axis 2 and axis 3 explained $12.6 \%$ and $11 \%$ of the total observed variability, respectively, based on the RanGAP2 dissimilarity matrix. The dataset was divided into the two clades, A and B according to the genome formula, the clade A correspond to the species with the genome AA or AAAA. The lack of structure in "clade A" may result partially from the high variability observed within accessions. Analysis of molecular variance (AMOVA) showed that the intra-accession variability explained more than $67 \%$ of the total variability; variability observed among species and among geographical origin groups (Peru, Argentina, Bolivia, Colombia, Mexico, USA and Europe) explained $26.62 \%$ and $12.82 \%$ of the total variability, respectively (Table 2).

\section{Identification of positions of functional relevance in RanGAP2}

Despite the low nucleotide diversity (1.3\%) observed along the Solanum RanGAP2 sequence dataset, we previously 
Table 1 Nucleotide and haplotype variability within the 18 Solanum species studied

\begin{tabular}{|c|c|c|c|c|c|c|c|c|c|}
\hline Species & $\begin{array}{c}\text { Wild / } \\
\text { cultivated }\end{array}$ & $\begin{array}{l}\text { Genome } \\
\text { formula* }\end{array}$ & $\begin{array}{l}\text { \# of } \\
\text { acc. }\end{array}$ & $\begin{array}{l}\text { \# of } \\
\text { seq. }\end{array}$ & pi & $\begin{array}{c}\text { \# of } \\
\text { haplotypes }\end{array}$ & $\begin{array}{c}\text { \# of segregating } \\
\text { sites }\end{array}$ & D Tajima & $\begin{array}{c}\% \mathrm{NS} \\
\text { mutations }\end{array}$ \\
\hline S. berthaultii & wild & AA & 2 & 4 & 0.0019 & 4 & 6 & -0.314 & $33.30 \%$ \\
\hline S. trifidum & wild & BB & 2 & 3 & 0.0020 & 3 & 5 & ND & $40.00 \%$ \\
\hline S. chacoense & wild & AA & 2 & 2 & 0.0024 & 2 & 4 & ND & $25.00 \%$ \\
\hline S. kurtzianum & wild & AA & 1 & 2 & 0.0024 & 2 & 4 & ND & $25.00 \%$ \\
\hline S. tarijense & wild & AA & 2 & 3 & 0.0028 & 2 & 7 & ND & $71.40 \%$ \\
\hline S. phureja & cultivated & AA & 2 & 4 & 0.0029 & $4 a$ & 9 & -0.153 & $33.30 \%$ \\
\hline S. fendleri & wild & AABB & 1 & 3 & 0.0048 & 3 & 12 & ND & $58.30 \%$ \\
\hline S. braschistotrichum & wild & BB & 2 & 4 & 0.0052 & 4 & 16 & -0.07 & $68.80 \%$ \\
\hline S. sparsipilum & wild & AA & 2 & 4 & 0.0068 & 4 & 21 & -0.108 & $57.10 \%$ \\
\hline S. spegazzinii & wild & AA & 7 & 13 & 0.0072 & $13 b$ & 55 & -1.4 & $47.30 \%$ \\
\hline S. stoloniferum & wild & AABB & 2 & 7 & 0.0093 & 7 & 36 & 0.286 & $69.40 \%$ \\
\hline S. cardiophyllum & wild & BB & 2 & 4 & 0.0099 & 4 & 29 & 0.445 & $41.40 \%$ \\
\hline S. gourlayi & wild & AAAA & 2 & 8 & 0.0109 & 8 & 55 & -0.789 & $50.90 \%$ \\
\hline S. vernei & wild & AA/AAAA & 6 & 16 & 0.0110 & $15 b c$ & 61 & -0.148 & $42.60 \%$ \\
\hline $\begin{array}{l}\text { S. tuberosum ssp } \\
\text { andigena }\end{array}$ & cultivated & AAAA & 12 & 46 & 0.0121 & $39 a$ & 120 & -1.177 & $56.70 \%$ \\
\hline $\begin{array}{l}\text { S. tuberosum ssp } \\
\text { tuberosum }\end{array}$ & cultivated & AAAA & 4 & 16 & 0.0124 & $14 c$ & 74 & -0.112 & $45.90 \%$ \\
\hline S. polytrichon & wild & AABB & 1 & 3 & 0.0124 & 3 & 31 & ND & $64.50 \%$ \\
\hline S. stenotomum & cultivated & AA & 2 & 4 & 0.0137 & 4 & 43 & -0.275 & $46.50 \%$ \\
\hline S. bulbocastanum & wild & BB & 1 & 1 & - & 1 & ND & ND & \\
\hline Total & & & & 147 & 0.0134 & 133 & & $\begin{array}{c}\text { all NS > } \\
10 \%\end{array}$ & $60.50 \%$ \\
\hline
\end{tabular}

Acc: accessions, seq: sequence, NS:non-synonymous, ND : not determined.

Three pairs of species (a: S. tuberosum ssp andigena/S. phureja, b: S. vernei/S. spegazzinii and c: S. tuberosum ssp tuberosum/S. vernei) had one common haplotype.

* Genome formulae proposed by Matsubayashi [25].

noted that nearly $50 \%$ of the mutations observed correspond to non synonymous mutations. Overall, 178 positions distributed along the entire protein sequence appear to be affected by non synonymous mutations, however only 28 of them appear to affect more than two Solanum species and 19 out of these 28 (ie nt positions 98, 175, 191, 309, 316, 709, 712, 787, 965, 1056, 1112, 1122, 1129, $1198,1201,1316,1340,1401,1427)$ are located in either the WPP or LRR domains.

To identify functionally relevant variants among these 19 positions, we investigated whether evidence for positive selection pressure could be detected in our data, and carried out evolutionary analyses using either neutrality or $\mathrm{dN} / \mathrm{dS}$ tests. Neutrality tests (Tajima's D) were conducted at the intra-specific level in each of the investigated species, while $\mathrm{dN} / \mathrm{dS}$ tests were conducted at the inter-specific level using SLAC, FEL and PAML (M1, M2, M7 and M8 models) methods. Values showing an excess of rare variants were obtained for the Tajima'D statistic (Table 1), but none of these neutrality tests provided significant results that allow a clear distinction from neutrality. In $\mathrm{dN} / \mathrm{dS}$ methods, first using a reduced sequence dataset consisting of only one sequence per Solanum species (ie 18 RanGAP2 aligned sequences), we compared the four evolutionary models implemented in the CODEML program: M1 vs M2 and M7 vs M8. None of the positive selection models appeared to be better adapted than the null model $(2 \Delta \mathrm{l}=9.84$; NS $\mathrm{p}=0,001)$. However, using the total sequence dataset (the 147 RanGAP2 aligned sequences), the positive selection models appear better adapted $(2 \Delta \mathrm{l}>69.28$; $\mathrm{p}<0.001)$ and both the M2 and M8 models founded eight sites with $\mathrm{dN} / \mathrm{dS}$ values significantly $>1$ (Table 3 ). The polymorphisms at amino acid positions 106 and 237 were also identified by the FEL and/or SLAC methods (Table 3). However, SLAC and FEL also revealed, respectively, 38 and 52 sites significantly (posterior probability > 95\%) under negative (purifying) selection suggesting that RanGAP2 is not a gene evolving under positive selection.

It appears from these analyses that only two sites of interest (P/S 106 located in the WPP domain and F/L 237 located in the LRR domain) can be highlighted from the 19 sites previously identified. Furthermore, positions 


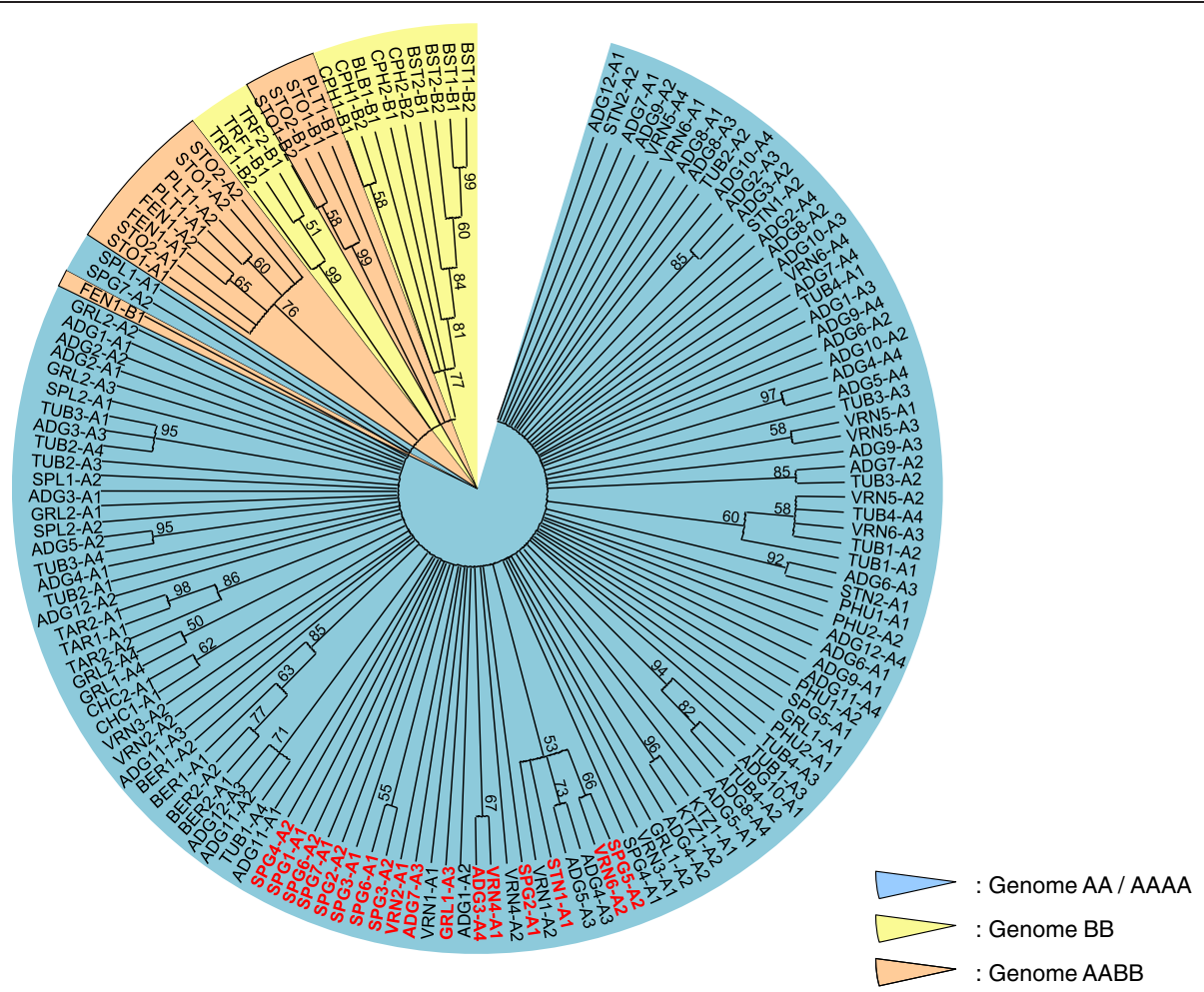

Figure 1 Phylogenetic analysis of Solanum section Petota RanGAP2 sequences using maximum likelihood methods. Phylogenetic analyses were conducted on the entire RanGAP2 sequence dataset with 1000 bootstraps. All branches with bootstraps lower than 50\% were collapsed. Genome formulae AA or AAAA, BB and AABB of the species studied are reported according to Matsubayashi [25] and highlighted by colored areas. The PF variants which present a proline residue at position 106 and phenylalanine residue at position 237 are represented in red.

106 and 237 were in linkage disequilibrium (D' value of 0.766) [26,27]). A proline residue at position 106 was found to be significantly more frequently associated with a phenylalanine residue at position 237 than with a leucine residue (exact Fisher test and chi-square test) (Table 4). The amino acid combination P106-F237 was identified in $77.9 \%$ of the $S$. spegazzinii sequences (10/13), $25 \%$ of the $S$. stenotomum sequences $(1 / 4), 18.7 \%$ of the $S$. vernei species (3/16), $12.5 \%$ of the $S$. gourlayi sequences $(1 / 8)$ and in $4.3 \%$ of the $S$. tuberosum spp andigena sequences (2/46). These five species belong to "clade-A". Despite the lack of structure within "clade-A", these 17 sequences all clustered close to each other (Figure 2) and correspond to 14 Solanum accessions that all belong to the Hawkes series of wild Tuberosa or cultivated Tuberosa. This probably explains the phylogenetic proximity of these 17 sequences with the amino acid combination P106-F237.

In order to test whether the $\mathrm{P} / \mathrm{S} 106$ and/or F/L 237 polymorphisms affect the function of GPA2, we tested whether RanGAP2 variants harboring different combinations at these two positions might allow GPA2 to gain recognition of previously unrecognized versions of GPRBP-1 and/or allow it to work more efficiently. Five variants of RanGAP2 were used in our experiments: VRN2-A1 ( $\triangle 516-518)$, which has a three amino acid deletion; STN1-A1 (P106 and F237), ADG4-A2 (S106 and L237), ADG8-A3 (P106 and L237) and GRL1-A2 (S106 and F237). Each RanGAP2 variant was transiently expressed in $N$. benthamiana leaves with Gpa2 and the Rook-4 (unrecognized) or Rook-6 (recognized) Gp-Rbp1 variants. In all cases, a HR was obtained when Rook-6 was expressed with Gpa2 together with one of the five RanGAP2 variants (Figure 3A). A weak HR was observed when the empty vector (EV) is used most probably due to the endogenous tobacco RanGAP2 that remains. No HR was observed when Rook-4 was coexpressed with Gpa2 alone or with Gpa2 in combination with any of the tested RanGAP2 variants (Figure 3A). Thus no gain of recognition of Rook-4 by Gpa 2 was conferred by polymorphisms observed at positions 106 and 237 or by the three amino-acid deletion in RanGAP2. When using $C P$ variants of PVX and $R x$ (instead of $G p-R b p-1$ variants and Gpa2) with the same five RanGAP2 variants similar results were obtained (ie an HR was observed with the recognized "TK" $\mathrm{CP}$ variant expressed with $R x$ but no HR was obtained for the "KR" $\mathrm{CP}$ variant, regardless of the RanGAP2 variants used) 


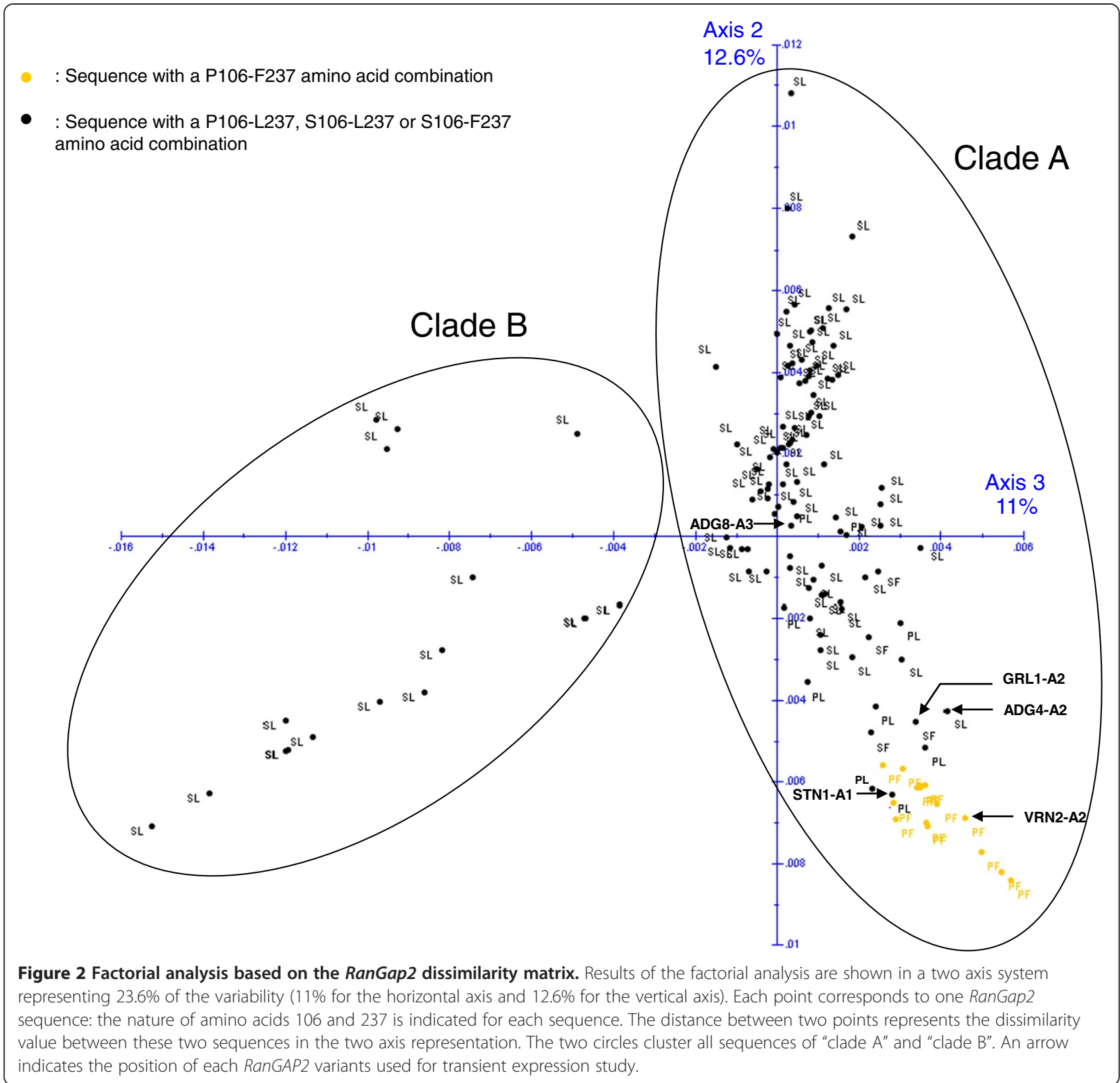

(data not shown). Thus, natural variation at positions 106 and 237 also has no effect on $R x$ recognition of the "KR" variant of the PVX CP.

Despite the detection by immunoblotting of similar RanGAP2 levels of all variants (Figure 3B) it appeared that the intensity of the HR observed with the positive control Rook- 6 varied depending on the RanGAP2 variant expressed. Indeed, the $\mathrm{HR}$ obtained in transient Agrobacterium transformations with variant ADG4-A2 (S106 - L237) and VRN2-A1 ( $\Delta 516-518)$ was consistently stronger than that obtained with the three other RanGAP2 variants (Figure 3A). It thus appeared that the most common amino acid combination S106-L237 seemed to be the most effective at triggering the HR, which ensued from the recognition of avirulent $G p-R b p$ 1 Rook-6.

\section{Discussion}

RanGAP2: a conserved gene involved in plant-pathogen interactions

Solanum RanGAP2 variants appear to show a high degree of conservation. With the exception of only one of the 147 RanGAP2 sequences obtained in this study (which showed a three amino acid in-frame deletion in the $\mathrm{N}$ terminus), all others have the same length (1662 bp ORF) and are characterized by a WPP domain at the 5'end (corresponding to amino acids 14 to 109) and ten LRRs of 28 amino acids each. Their overall 
Table 2 AMOVA of the RanGAP2 dataset using two different partitioning criteria: species or geographic origin (A)

\begin{tabular}{ccccc} 
Source of variation & Degree of freedom & Sum of squares & Variance components & Percentage of variation \\
\hline Among groups & 17 & 530.2 & 3.17 & 26.62 \\
Among genotypes within groups & 37 & 372.9 & 0.72 & 6.02 \\
Within genotypes & 93 & 745.2 & 8.01 & 67.36 \\
Total & 147 & 1648.3 & 11.9 &
\end{tabular}

(B)

\begin{tabular}{ccccc} 
Source of variation & Degree of freedom & Sum of squares & Variance components & Percentage of variation \\
\hline Among groups & 6 & 232.607 & 1.49236 & 12.82 \\
Among genotypes within groups & 41 & 554.571 & 2.09563 & 18 \\
Within genotypes & 79 & 636.483 & 8.05675 & 69.18 \\
Total & 126 & 1423.661 & 11.64474 &
\end{tabular}

The Analysis of MOlecular Variance (AMOVA) was carried out considering (A) 18 Solanum species or (B) seven geographical origins (Peru, Argentina, Bolivia, Colombia, Mexico, USA, Europe). In each case, the variance was calculated among the different groups, among the genotypes within each group and within all genotypes. In the AMOVA considering geographical origin, 21 sequences with an unknown geographical origin were removed from the dataset.

structure is also well conserved among the 55 accessions of the 18 Solanum species studied; the two most divergent alleles (BST1-B2 and TUB2-A3) are still 97\% identical at the nucleotide level.

RanGAP2 shows less sequence size variations and a lower polymorphism rate (31.4\% vs $19 \%)$ than $G p-R b p-1$ [20], the gene encoding for the effector recognized by GPA2. Furthermore RanGAP2 also appears to be less variable than the housekeeping gene nitrate reductase, whose variability was evaluated in various Solanum species [28]. The estimated pi value for two S. stoloniferum accessions (eight sequences) and one S. sparsipilum accession (two sequences) is at least twice as high for the nitrate reductase gene [28] than that estimated in these two species for the RanGAP2 gene (two S. stoloniferum and one $S$. spegazzinii accession were also represented in our dataset).

The phylogenetic tree generated with the 147 RanGAP2 sequences correlates well with several phylogenies obtained with neutral markers or using DNA sequences of single copy housekeeping and chloroplast genes [28-32]. We can also note that RanGAP2 sequences of the three allo-tetraploid species S. stoloniferum, S. fendleri and $S$. polytrichon are phylogenetically related. This is consistent with the study of Jacobs et al., [31] which considered these three taxa as a single species. Our RanGAP2 dataset also confirms a lack of phylogenetic structure in Solanum section Petota partly attributed to numerous interspecific hybridizations at both the diploid and polyploid levels [28]. This can explain how three pairs of species (S. tuberosum ssp andigena/S. phureja, S. tuberosum ssp tuberosum/S. vernei and S. vernei/S. spegazzinii) have one RanGAP2 haplotype in common.

Positive selection hallmarks in RanGAP2 were searched using the Tajima's D statistic. Though negative values were mostly obtained for the species investigated, none appear significantly different from neutral expectations. Positive values of the Tajima's D statistic were observed in

Table 3 Analysis of RanGAP2 for positively selected sites

\begin{tabular}{cccccc}
\hline \multirow{2}{*}{ Animo acid position } & Domain in the RanGAP2 gene & M2 & M8 & \multicolumn{3}{c}{ Used methods for detecting sites of interest } \\
\cline { 3 - 6 } 33 & WPP & $0.999^{* *}$ & $1.000^{* *}$ & Not identified & Not identified \\
106 & WPP & $0.999^{* *}$ & $1.000^{* *}$ & $0.992^{*}$ & $0.972^{*}$ \\
165 & LRR & $0.957^{*}$ & $0.991^{* *}$ & 0.937 & 0.938 \\
237 & LRR & $0.999^{* *}$ & $1.000^{* *}$ & $0.991^{*}$ & 0.901 \\
238 & LRR & $0.961^{*}$ & $0.988^{*}$ & Not identified Not identified \\
377 & LRR & $0.976^{*}$ & $0.995^{* *}$ & Not identified & Not identified \\
447 & LRR & $0.985^{*}$ & $0.995^{* *}$ & 0.927 & Not identified
\end{tabular}

Using a dataset comprising both intra- and inter-specific sequences, probabilities of eight sites of RanGAP2 being under positive selection according to the M2 and M8 models of the CODEML program of PAML (Phylogenetic Analyses by Maximum Likelihood) and the FEL (Fixed Effects Likelihood) and SLAC methods (Single Likelihood Ancestor Counting), both available through the DataMonkey web interface. 
Table 4 Linkage disequilibrium between residues at positions 106 and 237 in RanGAP2

\begin{tabular}{lcc}
\hline (A) & & \\
haplotype 106-237 & Observed & Expected \\
\hline P-F & 17 & 4 \\
P-L & 10 & 23 \\
S-F & 4 & 17 \\
S-L & 116 & 103
\end{tabular}

(B)

\begin{tabular}{ccc} 
D $^{\prime}$ & Fisher test & Chi-square test \\
\hline 0.766 & $\mathrm{p}<0.001$ & $\mathrm{p}<0.001$ \\
\hline
\end{tabular}

Theoretical combinations of proline (P) and serine (S) at position 106 with phenylalaline (F) and leucine (L) were calculated using the frequency of each amino acid in the total dataset and assuming that the nature of an amino acid at position 106 is not linked to the nature of an amino acid at position 237. These theoretical combinations were compared to the observed combinations in the dataset (A). Linkage disequilibrium between residues at positions 106 and 237 was evaluated using the $D^{\prime}$ value, the significance of which was tested with Fisher and Chi-square tests (B).

S. cardiophyllum (genome $\mathrm{BB}$ ) and its sister derived species $S$. stoloniferum (genome AABB). It is tempting to speculate that the traces of balancing selection can be linked to the $\mathrm{BB}$ genome. However calculation of the values of the Tajima's D statistic was hampered in most of the other species corresponding to the $\mathrm{BB}$ genome by the lack of at least four different alleles. We also took advantage of the sequencing of RanGAP2 in multiple species to investigate the evolutionary constraints acting on this gene based on $\mathrm{dN} / \mathrm{dS}$ ratios. Using a reduced dataset made of one consensus sequence per species in order to consider only inter-specific sequences as is recommended [33-35], RanGAP2 does not appear to be under positive selection and appears rather to be under strong evolutionary constraints as previously suggested by its low diversity and as also confirmed by the numerous (at least 38 ) sites under purifying selection identified by both SLAC and FEL analysis. However, using the complete sequence dataset we were able to identify two key positions (aa position 106 and 237) that are predicted by at least two different methods to be under positive selection. One possible explanation of this pattern is that alleles displaying these two amino acid changes, also found in linkage disequilibrium, have passed through the different Solanum species as an advantageous combination. In a similar way, key residues under positive selection were detected in the translation factor eIF4E, which is also involved in resistance to potyviruses in pepper, using a data set comprising both intra- and inter-specific sequences [36,37]. Similarly to eIF4E, the two key positions identified in RanGAP2 using the whole RanGAP2 dataset could be linked to its role in the incompatible resistance interaction between $\mathrm{CP}$ and Rx or Gp-RBP-1 and GPA2.

\section{Impact of RanGAP2 polymorphism on plant-parasite interactions}

Although GP-RBP-1 has not been definitively shown to physically interact with RanGAP2, this protein is thought to play a role in mediating recognition of both PVX CP and GP-RBP-1 via the LRRs of Rx and GPA2, respectively, as proposed by the bait and switch model and by artificial tethering experiments $[5,19,38]$. Potential for variation in effector recognition due to variation in bait proteins is suggested from studies of the tomato NB-LRR Prf, which recognizes Avr proteins from Pseudomonas syringae through its cofactor, the Pto kinase [21]. Multiple Pto-like proteins are encoded in the tomato genome, and it has been shown that Prf recognition specificity is altered depending on which homologue it interacts with $[39,40]$. As such, variability in RanGAP2 could affect GPA2 - RBP1 interactions. Sites under positive selection are often key positions in resistance interactions and, more specifically, in the recognition of Avr proteins [19,36,41]. We tested if the nine nucleotide deletion in the $\mathrm{N}$-terminus of RanGAP2 and/or the variability observed at sites 106 and 237 could alter or enhance GPA2-mediated recognition of GP-RBP-1 by transient expression in tobacco leaves.

The GP-RBP-1 "Rook-4" was never recognized by GPA2 regardless of which RanGAP2 variants were coexpressed. This is consistent with previous results showing that although different GP-RBP-1 variants elicited GPA2-dependent HRs to varying degrees, ultimately, polymorphism at position 187 of GP-RBP-1 [19] was the only variation which could explain GPA2-mediated recognition of GP-RBP-1. Similar results were obtained on the recognition of the $\mathrm{CP}$ variant "KR", which is recognized only very poorly by $\mathrm{Rx}[42,43]$. As a weak HR is obtained with the empty vector, these results should be interpreted carefully because in addition to the RanGAP2 variants tested endogenous $N$. benthamiana RanGAP2 are expressed in the agro-infiltrated leaves and could affect the interaction.

Sites under positive selection in the LRR domains of $R$ genes do not always localize to the R/Avr interface [41,44]. In addition some amino acids in the LRR domain modulate the resistance by interacting with host factors [45]. Thus, diversity observed at RanGAP2 sites 106 and 237 (sites detected with software usually used to find positive selection) and the three amino acid deletion ( $\Delta 516-518)$ may affect the resistance interaction through a mechanism other than recognition. Position 106 localizes to the WPP domain, which physically interacts with the CC domain of both $\mathrm{Rx}$ and GPA2 $[16,19,46]$ which has recently been shown to be sufficient to activate $\mathrm{Rx}$ fragments upon co-expression [22]. Diversity at position 106 could thus affect the three-dimensional conformation of the entire GPA2/RanGAP2/GP-RBP-1 complex 

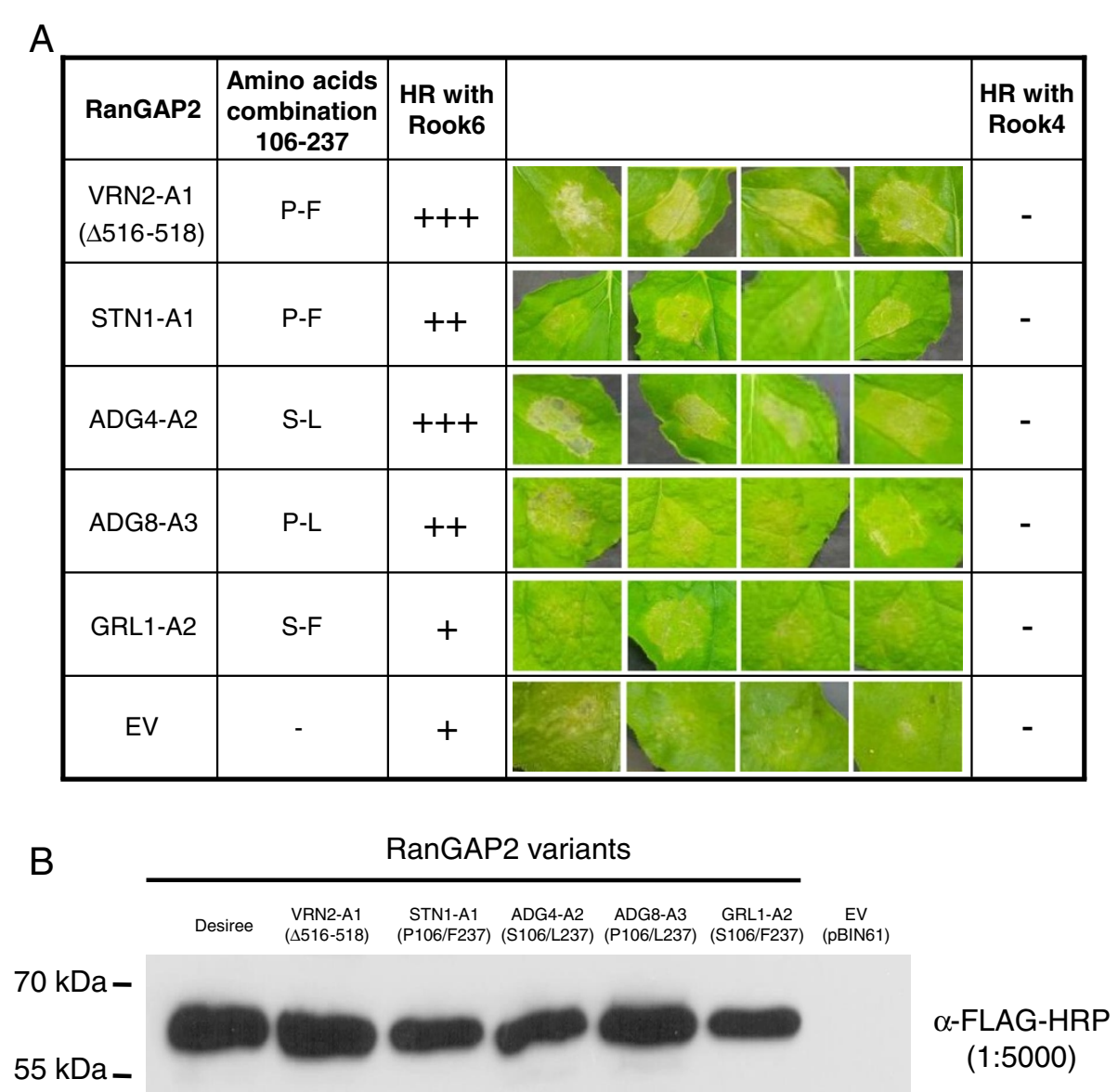

Figure 3 RanGAP2 variability affects the strength of the Gpa2-mediated HR in Nicotiana benthamiana leaves. (A) The five RanGAP2 variants and an empty vector (EV) were transiently expressed in N. benthamiana leaves with Gpa2 and either the Gp-Rbp-1 Rook-6 and Rook-4 variants. The strength of the hypersensitive response obtained for each RanGAP2 variant is indicated as follows: (+++) complete collapse and rapid desiccation of the infiltration patch within two days, $(++)$ complete collapse of the infiltration patch by three days post-infiltration, $(+)$ slow and incomplete collapse with residual live cells. (B) Immunoblot with horse radish peroxidase-conjugated anti-FLAG antibody demonstrating relative protein levels of the five transiently expressed RanGAP2 proteins. These five RanGAP2 variants include VRN2-A1 which has a three amino acid deletion (4516-518), STN1-A1 (P106 and F237), ADG4-A2 (S106 and L237), ADG8-A3 (P106 and L237) and GRL1-A2 (S106 and F237) which represent the four haplotype combinations at the 106 and 237 positions. An empty vector (EV) was used as a negative control.

and thus contribute to the initiation of defense mechanisms by facilitating transition from an auto-inhibited to an active form of the NB-LRR protein [5].

Our results also resemble those recently obtained in tomato on the decoy RCR3 for which the functional assay of several alleles shows that the polymorphisms observed do not play a role in pathogen (C. fulvum) recognition but are responsible of the modulation of defence response upon effector recognition [13]. However, while $R C R 3$ was characterized by balancing selection, RanGAP2 experienced rather purifying selection. This difference in rate of evolution can be related to the difference of either the variation in time and space of the selection pressure exerted by nematodes vs fungus or the ability of these two co-factors to interact physically with pathogen effectors. Indeed, RCR3 is able to bind to AVR2 proteins of the fungus [47] and was also showed recently to be able to bind to a nematode effector [48] while it is still unclear if RanGAP2 is able to bind GPRBP-1. Artificial tethering of RanGAP2 and GP-RBP-1 through YFP complementation allowed these two proteins to interact physically but did not lead to the recognition of "Rook-4" by Gpa2 [19]. On the other hand, tethering of RanGAP2 to a GP-RBP-1 with a proline residue at position 187 (recognized by GPA2) enhances Gpa2-mediated HR [19]. Consequently, it appears that the $\mathrm{P} / \mathrm{S}-187$ position of GP-RBP-1 qualitatively determines whether GPA2 will recognize RBP-1, whereas the RanGAP2 positions 106 and/or 237 and the three amino acid deletion ( $\Delta 516-518)$ may enhance the efficiency of this recognition, resulting in a faster and more intense HR.

Whether the strength of this recognition is a consequence of only the GPA2 + RanGAP2 physical interaction or also that of a RanGAP2 + GP-RBP-1 physical 
interaction remains to be elucidated. However, the observed rate of evolution in RanGAP2 appears to be not in support of a potential physical interaction with so divergent and polymorphic nematode and virus effectors. It seems rather that the different variants of RanGAP2 allow $R x$ or Gpa2 to function more efficiently independent of the recognition of the pathogen effector. This would predict that the diversity of recognition cofactors represents an additional level of complexity in plantpathogen interactions that merits further study.

\section{Conclusions}

In this study sequence variability of the ETI cofactor RanGAP2 was investigated for the first time and the potential of variants of this gene to enhance resistance to nematodes or viruses was examined. We identified a three amino-acids deletion and two sites (one in the WPP domain and one in the LRR domain) that should help to define variants of interest. Variability observed in theses sites/region of RanGAP2 does not seem to enable recognition of virulent variants of GP-RBP-1 by GPA2 but appears to enhance the recognition of avirulent variants of GP-RBP-1.

\section{Methods}

Plant materials, DNA isolation, amplification and cloning

Nicotiana benthamiana seeds were germinated and plants were grown for 5 weeks in a Conviron growth cabinet (Conviron, http://www.conviron.com), where conditions were as follow: $21^{\circ} \mathrm{C} / 21^{\circ} \mathrm{C}$ day/night, 16 -h day, $60 \%$ relative humidity, and light intensity of $100 \mu \mathrm{mol} \mathrm{m} \mathrm{m}^{-2} \mathrm{~s}^{-1}$.

Fifty five diploid and tetraploid accessions from 18 Solanum species belonging to the plastid DNA clade 2 and 4 of section Petota [29] were examined (Table 5). Total DNA from each accession was isolated using the protocol described by Fulton et al. [49]. A Genbank RanGAP2 S. tuberosum sequence (http://www.ncbi. nlm.nih.gov/nuccore/AM411448) was used to design primers in the 5' and 3' ends of the $1662 \mathrm{pb}$ intronless gene. PCR reactions were carried out in a final volume of $25 \mu \mathrm{L}$ using $30 \mathrm{ng}$ of template genomic DNA, $0.5 \mu \mathrm{M}$ of the RanGap2JC1-F forward primer (5'-ATGGATGCCA CAACAGCTAA-3'), $0.5 \mu \mathrm{M}$ of the RanGap2stop reverse primer (5'-CTAATTGCTATCTGGTGTGTCAAG-3'), $0.2 \mathrm{mM}$ of each dNTPs, 0.6 unit of Taq polymerase (Takara Ex $\mathrm{Taq}^{\mathrm{TM}}$ ), and $2.5 \mu \mathrm{L}$ of the provided $10 \times$ Ex Taq Buffer. The PCR protocol was $5 \mathrm{~min}$ at $98^{\circ} \mathrm{C}$, followed by 35 cycles of: $10 \mathrm{sec}$ at $98^{\circ} \mathrm{C}, 30 \mathrm{sec}$ at $51^{\circ} \mathrm{C}$ and $1 \mathrm{~min}$ $45 \mathrm{sec}$ at $72^{\circ} \mathrm{C}$ and a final step of $10 \mathrm{~min}$ at $72^{\circ} \mathrm{C}$.

PCR products were cloned using the Strataclone ${ }^{\mathrm{Tm}}$ PCR cloning Kit (Stratagene) according to the manufacturer's instructions. Ten transformed colonies per tetraploid accession and five per diploid accession were selected and used to amplify the insert. PCR reactions were performed in a final volume of $60 \mu \mathrm{L}$, containing $0.5 \mu \mathrm{M}$ of M13 forward and reverse primers, $0.2 \mathrm{mM}$ of each dNTPs, 1.5 unit of Taq polymerase (Takara Ex Taq ${ }^{\mathrm{TM}}$ ) and $6 \mu \mathrm{L}$ of the $10 \times$ Ex Taq Buffer. The PCR protocol was $5 \mathrm{~min}$ at $98^{\circ} \mathrm{C}$, followed by 35 cycles of $10 \mathrm{sec}$ at $98^{\circ} \mathrm{C}$, $30 \mathrm{sec}$ at $55^{\circ} \mathrm{C}, 2 \mathrm{~min} 30 \mathrm{~s}$ at $72^{\circ} \mathrm{C}$ and a final step of $10 \mathrm{~min}$ at $72^{\circ} \mathrm{C}$. PCR products were sequenced by Genoscreen using the following three primers: RanGap2JC695-R reverse primer (5' CTAACTCCCTTCTCACCCAGA 3') for the 3'end sequence, RanGap2JC435-F forward primer (5' GCCATTAAAAGAGCCTGGAA 3') for the 5' end sequence and RanGap2JC1015-F forward primer (5' GGTCCAGAAGTTGGTCTTGTGT 3') as an internal sequencing primer. All the sequences have been deposited to GenBank/EMBL databases under the following accession numbers HE681572 to HE681718. For each RanGAP2 allele, the EMBL number accession is reported in Additional file 1: Table S1.

\section{Sequence alignments and evolutionary analyses}

Previously obtained sequences were assembled using the cap contig assembly program of Bioedit [50]. This same module was used to construct the consensus sequence of RanGAP2 for each species. When possible, Mega5 software was used to manually correct ambiguous nucleotides based on the chromatograms [51]. RanGAP2 sequences were aligned using Mega5 [51] and the ClustalW (1.6) DNA weight matrix. Mega5 [51] was also used to find the best DNA substitution model fitting our dataset. Phylogenetic analyses on RanGAP2 sequences were carried out using, maximum likelihood and maximum parsimony methods and minimum evolution algorithms with the Tamura 3-parameter model [52] and a Gamma parameter of 0.163 . This model was the best model fitting our dataset and available in Mega5 software [51]. The robustness of the minimum evolution trees was evaluated by bootstrapping with 1000 repetitions. Motifs were detected in translated DNA sequences using SMART (Simple Modular Architecture Research Tool) [53]. The pi indicator (average number of nucleotide differences per site between two sequences), haplotype diversity was computed using DnaSP v5 software [54].

To examine whether RanGAP2 has evolved under positive selection we used the ratio of non-synonymous to synonymous substitution rates per site $(\omega=\mathrm{dN} / \mathrm{dS})$ estimated by site specific models implemented in the PAML package v 3.14 [55]. The tree used in PAML analysis was first obtained after running M0 in PAML (model $=0$ and NS sites $=0$. The CODEML program of PAML assigns a likelihood score to models for selection. A likelihood score for a model incorporating positive selection (M2 or M8) that is higher than that for a null model without positive selection (M1 or M7) is evidence 
Table 5 Detailed informations on the Solanum species analyzed in this study

\begin{tabular}{|c|c|c|c|c|c|c|c|c|c|c|}
\hline \multirow[b]{2}{*}{$\begin{array}{l}\text { Species (classification reviewed by Jacobs } \\
\text { et al., 2008) }\end{array}$} & \multirow[b]{2}{*}{$\begin{array}{l}\text { Genotype } \\
\text { code }\end{array}$} & \multirow[b]{2}{*}{ Accession } & \multirow[b]{2}{*}{$\begin{array}{l}\text { Ploidy } \\
\text { level }\end{array}$} & \multirow[b]{2}{*}{$\begin{array}{c}\text { Country of } \\
\text { origin }\end{array}$} & \multirow[b]{2}{*}{$\begin{array}{l}\text { G. pallida } \\
\text { Rce }\end{array}$} & \multirow[b]{2}{*}{$\begin{array}{l}\text { PVX } \\
\text { Rce }\end{array}$} & \multicolumn{4}{|c|}{$\begin{array}{l}\text { RanGap2 106- } \\
237 \text { haplotype }\end{array}$} \\
\hline & & & & & & & $\mathrm{PF}$ & $\mathrm{PL}$ & SF & SL \\
\hline \multirow[t]{12}{*}{ S. tuberosum spp. andigena } & ADG1 & 885.233 .8 & $4 \times$ & Peru & - & +++ & & $x$ & & $x$ \\
\hline & ADG2 & 885.249. 1 & $4 \times$ & Bolivia & - & +++ & & & & $x$ \\
\hline & ADG3 & 885.250. 1 & $4 \times$ & Argentina & - & +++ & $x$ & $x$ & & $x$ \\
\hline & ADG4 & 885.262 .7 & $4 \times$ & Peru & - & - & & $x$ & & $x$ \\
\hline & ADG5 & 885.408 .14 & $4 \times$ & - & $-(* *)$ & +++ & & $x$ & & $x$ \\
\hline & ADG6 & 885.257 .4 & $4 \times$ & Peru & - & - & & & & $x$ \\
\hline & ADG7 & 885.259. 9 & $4 \times$ & Peru & - & - & $x$ & & & $x$ \\
\hline & ADG8 & 885.260 .11 & $4 \times$ & Peru & - & - & & $x$ & & $x$ \\
\hline & ADG9 & 885.261 .3 & $4 \times$ & Peru & - & +++ & & & & $x$ \\
\hline & ADG10 & 885.263 .4 & $4 \times$ & Peru & - & +++ & & & & $x$ \\
\hline & ADG11 & 885.264 .7 & $4 \times$ & Peru & - & - & & & & $x$ \\
\hline & ADG12 & 885.255 .2 & $4 \times$ & Mexico & - & - & & & & $x$ \\
\hline \multirow[t]{2}{*}{ S.berthautii } & BER1 & 885.282 .8 & $2 x$ & Bolivia & - & - & & & & $x$ \\
\hline & BER2 & $88 S .452 .8$ & $2 x$ & - & - & +++ & & & & $x$ \\
\hline S. bulbocastanum & BLB1 & O0S. 32. 11 & $2 x$ & Mexico & - & - & & & & $x$ \\
\hline \multirow[t]{2}{*}{ S. brachistotrichum (S. stenophyllidium) } & BST1 & OOS. 17.5 & $2 x$ & Mexico & - & - & & & & $x$ \\
\hline & BST2 & OOS. 19. 1 & $2 x$ & Mexico & - & - & & & & $x$ \\
\hline \multirow[t]{2}{*}{ S. chacoense } & $\mathrm{CHC1}$ & $88 S .456 .8$ & $2 x$ & Argentina & $-\left(^{*}\right)$ & - & & & & $x$ \\
\hline & $\mathrm{CHC2}$ & 74S. 33.3 & $2 x$ & $?$ & $?$ & $?$ & & & & $x$ \\
\hline \multirow[t]{2}{*}{ S. cardioophyllum } & $\mathrm{CPH} 1$ & OOS. 42.3 & $2 x$ & Mexico & - & - & & & & $x$ \\
\hline & $\mathrm{CPH} 2$ & O0S. 43. 21 & $2 x$ & Mexico & - & - & & & & $x$ \\
\hline S. fendleri (S. stoloniferum) & FEN1 & OOS. 56.1 & $4 \times$ & USA & - & - & & & & $x$ \\
\hline \multirow[t]{2}{*}{ S. gourlayi } & GRL1 & $88 S .315 .18$ & $4 \times$ & Argentina & - & +++ & $x$ & & $x$ & $x$ \\
\hline & GRL2 & $88 S .495 .5$ & $4 \times$ & Bolivia & +++ & +++ & & & & $x$ \\
\hline S. kurtzianum & KTZ1 & 88S.499. 10 & $2 x$ & Argentina & $+++(*)$ & - & & & & $x$ \\
\hline \multirow[t]{2}{*}{ S. phureja } & PHU1 & 885.214 .14 & $2 x$ & Colombia & - & - & & & & $x$ \\
\hline & $\mathrm{PHU} 2$ & 785.222. 8 & $2 x$ & Peru & - & +++ & & & & $x$ \\
\hline S. polytrichon (S. stoloniferum) & PLT1 & OOS. 69.8 & $4 \times$ & MEXICO & - & - & & & & $x$ \\
\hline \multirow[t]{7}{*}{ S. spegazzinii } & SPG1 & 785.236. 2 & $2 x$ & Argentina & +++ & - & $x$ & & & \\
\hline & SPG2 & 88S.332.2 & $2 x$ & Argentina & +++ & - & $x$ & & & \\
\hline & SPG3 & 885.334 .19 & $2 x$ & Argentina & +++ & - & $x$ & & & \\
\hline & SPG4 & 885.510 .9 & $2 x$ & Argentina & +++ & - & $x$ & & $x$ & \\
\hline & SPG5 & $88 S .511 .7$ & $2 x$ & Argentina & +++ & - & $x$ & & $x$ & \\
\hline & SPG6 & 885.514 .3 & $2 x$ & Argentina & +++ & - & $x$ & & & \\
\hline & SPG7 & 885.524 .24 & $2 x$ & Argentina & +++ & - & $x$ & & & $x$ \\
\hline \multirow[t]{2}{*}{ S. sparsipilum } & SPL1 & 885.329 .18 & $2 x$ & Bolivia & +++ & - & & & & $x$ \\
\hline & SPL2 & 995. 74. 9 & $2 x$ & Peru & - & - & & & & $x$ \\
\hline \multirow[t]{2}{*}{ S. stenotomum } & STN1 & 74S. 14.1 & $2 x$ & Peru & - & - & $x$ & & & $x$ \\
\hline & STN2 & 74S. 16.3 & $2 x$ & Bolivia & - & - & & & & $x$ \\
\hline \multirow[t]{2}{*}{ S. stoloniferum } & STO1 & 69S.107. 15 & $4 \times$ & $?$ & $?$ & $?$ & & & & $x$ \\
\hline & STO2 & O0S. 83.13 & $4 \times$ & Mexico & - & - & & & & $x$ \\
\hline
\end{tabular}


Table 5 Detailed informations on the Solanum species analyzed in this study (Continued)

\begin{tabular}{|c|c|c|c|c|c|c|c|c|c|c|}
\hline \multirow[t]{2}{*}{ S. tarijense } & TAR1 & 905.6 .4 & $2 x$ & Argentina & - & - & & & & $x$ \\
\hline & TAR2 & 90S. 14. 31 & $2 x$ & Argentina & - & - & & & & $x$ \\
\hline \multirow[t]{2}{*}{ S. trifidum } & TRF1 & 00S. 99.3 & $2 x$ & Mexico & - & - & & & & $x$ \\
\hline & TRF2 & 00S.100. 20 & $2 x$ & Mexico & - & - & & & & $x$ \\
\hline \multirow[t]{4}{*}{ S. tuberosum ssp. tuberosum } & TUB1 & Desiree & $4 \times$ & Europe & - & - & & & & $x$ \\
\hline & TUB2 & Darwina & $4 \times$ & Europe & $+++(* *)$ & +++ & & & & $x$ \\
\hline & TUB3 & Multa & $4 \times$ & Europe & $?$ & ++ & & & & $x$ \\
\hline & TUB4 & Glenna & $4 \times$ & Europe & $++\left({ }^{* *}\right)$ & +++ & & & & $x$ \\
\hline \multirow[t]{6}{*}{ S. vernei } & VRN1 & 74S. 32.1 & $2 x$ & $?$ & +++ & $?$ & & $x$ & $x$ & \\
\hline & VRN2 & 785.248. 1 & $2 x$ & Argentina & +++ & - & $x$ & & & $x$ \\
\hline & VRN3 & 885.342 .5 & $2 x$ & Argentina & +++ & - & & & & $x$ \\
\hline & VRN4 & 88S.530.14 & $2 x$ & Argentina & +++ & - & $x$ & $x$ & & \\
\hline & VRN5 & $\begin{array}{c}\text { AM } 78 \\
3778\end{array}$ & $4 x$ & $?$ & +++ & $?$ & & & & $x$ \\
\hline & VRN6 & SCRI 12380 & $4 \times$ & $?$ & +++ & $?$ & $x$ & & & $x$ \\
\hline
\end{tabular}

The species and country of origin of the 55 accessions used in this study are detailed in the table. The genotype code used in this study is indicated with the corresponding accession number of the considered genotype. G. pallida and PVX resistance (Rce) information is also included for each genotype. Resistance to G. pallida may have been evaluated only for pathotype $3(*)$ or pathotype $2\left(^{*}\right)$. These informations were obtained from either the Sturgeon Bay collection, Braunschweig Institute or INRA. The amino acid at position 106 and 237 for each RanGAP2 sequences obtained are also indicated in the table.

for positive selection. To identify the sites under positive selection we used several different methods including the Bayes Empirical Bayes implemented in CODEML, which calculates the posterior probabilities that each site fell into a different $\omega$ class, the Single-Likelihood Ancestor Counting (SLAC) [56] and the Fixed-Effects Likelihood (FEL) [56], both available through the DataMonkey web interface [57]. Linkage disequilibrium values between sites of interest were evaluated by calculating the " $D$ ' " value associated with its Fisher and Chi-square statistical tests, using DnaSP v5 software [54]. The intra- and inter-species /genotype variabilities were evaluated by AMOVA using Arlequin 3.1 software [58].

\section{Agrobacterium transient transformation assays}

The five RanGAP2 sequences STN1-A1 (P-106, F-237), ADG4-A2 (S-106, L-237), ADG8-A3 (P-106, L-237), GRL1-A2 (S-106, F-237) and VRN2-A1 ( $\Delta 516-518)$ were chosen to represent all the variability observed at the two sites 106 and 237. To generate RanGAP2 expression clones, the different inserts were ligated into the 5' XbaI and 3' BamHI sites of the pBIN61 binary vector series. For this, the five RanGAP2 sequences were amplified with forward primer RG2 $\times$ ba (5'AGTCTAGAACCACCATGGATGCCACAACAGCTAA3') and reverse primer RG2Bam (5'ATGGATCCATTGC TATCTGGTGTGTCAAGA-3') to add XbaI and BamHI restriction sites at 5' and the 3' ends of the PCR products. After purification on agarose gel, amplicons were first ligated into pGEM-T (Promega Easy Vector Systems), then digested with $\mathrm{XbaI}$ and $\mathrm{BamHI}$ and ligated into pBIN61 vector. An empty vector was used as a negative control. The "Rook-4", "Rook-6", "KR" and "TK" expression clones were obtained as previously described [19,59]. For transient protein expression, $N$. benthamiana plants were infiltrated by syringe with Agrobacterium tumefaciens strain C58C1 carrying the virulence plasmid $\mathrm{pCH} 32$ and the appropriate pBIN61 binary expression vector. Agrobacterium cultures were diluted to OD600 $=1$ and co-infiltrated at a final OD600 $=0.33$ (OD600=0.2 for western blotting). Plants were transferred to a growth chamber maintained with 16 -h light and 8 -h darkness at $20^{\circ} \mathrm{C}$ for three to five days. All experiments were repeated on at least three leaves of three different plants.

\section{Protein extraction and western blotting}

For protein extractions, leaf discs were grounded in liquid nitrogen and resuspended in $70 \mu \mathrm{l}$ of $1 \times$ sodium dodecy sulphate (SDS)-PAGE loading dye. Samples were heated at $95^{\circ} \mathrm{C}$ for three minutes and centrifuged at $18000 \times \mathrm{g}$ to get rid of cell debris. $35 \mu \mathrm{l}$ of cleared protein lysate was loaded on a $10.5 \%$ acrylamide gel and separated by SDSPAGE electrophoresis. Proteins were then transferred to polyvinylidene difluoride (PVDF) membranes (Bio-Rad, http://www.biorad.com) and blots were blocked for 90 min with Tris-buffered saline (TBS) containing 5\% (w/v) powdered skimmed milk and $0.1 \%(\mathrm{v} / \mathrm{v})$ Tween 20. For detection of RanGAP2 variants, blots were probed for 1 hour with horseradish peroxidase-conjugated antiFLAG (M2; Sigma, http://www.sigmaaldrich.com) antibodies diluted in TBS plus 1\% (w/v) powdered skimmed milk and $0.1 \%(\mathrm{v} / \mathrm{v})$ Tween 20. Antibodies dilution was 
1:5000. Blots were washed 4 times with TBS plus $0.1 \%$ $(\mathrm{v} / \mathrm{v})$ Tween 20 and epitope-tagged proteins were visualized using the ECL chemiluminescent system (Pierce, http://www.piercenet.com).

\section{Additional file}

Additional file 1: Table S1. Detailed informations on the different RanGAP2 alleles analysed in this study. For each RanGAP2 allele analysed, species and accession of origin, nature of the amino acids 106 and 237 and RanGAP2 allele EMBL number accession are indicated in the table.

\section{Competing interests}

The authors declare that they have no competing interests.

\section{Authors' contributions}

The study was conceived by JC, MJMD, MCK, PM and EG. JC obtained and analyzed the sequence dataset. JC, ME, and LPH carried out the transient expression assays and immunoblotting analyses. JC wrote the manuscript and MJMD, EG, LPH, PM and MCK proofread the manuscript. All authors read and approved the final manuscript.

\section{Acknowledgements}

We thank the genetic resource centre BrACySol (INRA Ploudaniel) for providing the Solanum accessions. We are grateful to Florence Esnault for critical reading of the manuscript. JC is supported by the Région de Bretagne through a three year PhD grant (nb 08005871). We thank the INRA departments "Génétique et Amélioration des Plantes" and "Santé des Plantes et Environnement" for their financial support. We also thank the Université Européenne de Bretagne for providing a grant to Jean Carpentier to visit the Université de Sherbrooke and all members of the Moffett lab for their support and input during this three month period. The Moffett lab is supported by funds from the National Sciences and Engineering Research Council of Canada.

\section{Author details}

${ }^{1}$ INRA, UMR 1349 IGEPP INRA, Agrocampus Ouest, Université Rennes1, Ploudaniel, Keraïber F.29260, France. ${ }^{2}$ Agrocampus Ouest, UMR 1349 IGEPP INRA, Agrocampus Ouest, Université Rennes1, Le Rheu F-35653, France. ${ }^{3}$ INRA, UMR 1349 IGEPP INRA/Agrocampus Ouest/Université Rennes1, Le Rheu F-35653, France. ${ }^{4}$ Université Sherbrooke, Dept Biol, Sherbrooke, PQ J1K 2R1, Canada. ${ }^{5}$ Université Européenne de Bretagne, Brittany, Rennes cedex F-35042, France.

Received: 21 November 2012 Accepted: 15 April 2013 Published: 19 April 2013

\section{References}

1. Jones JD, Dangl JL: The plant immune system. Nature 2006, 444(7117):323-329.

2. Hammond-Kosack KE, Parker JE: Deciphering plant-pathogen communication: fresh perspectives for molecular resistance breeding Curr Opin Biotechnol 2003, 14(2):177-193.

3. Flor $\mathrm{HH}$ : Host-parasite interaction in flax rust - its genetics and other implications. Phytopathology 1955, 45(12):680-685.

4. Van der Biezen EA, Jones JD: Plant disease-resistance proteins and the gene-for-gene concept. Trends Biochem Sci 1998, 23(12):454-456.

5. Collier SM, Moffett P: NB-LRRs work a "bait and switch" on pathogens. Trends Plant Sci 2009, 14(10):521-529.

6. Dangl $\mathrm{J}$, Jones JDG: Plant pathogens and integrated defence responses to infection. Nature 2001, 411(6839):826-833.

7. van der Hoorn RA, Kamoun S: From guard to decoy: a new model for perception of plant pathogen effectors. Plant Cell 2008, 20(8):2009-2017.

8. Bakker EG, Toomajian C, Kreitman M, Bergelson J: A genome-wide survey of R gene polymorphisms in Arabidopsis. Plant Cell 2006, 18(8):1803-1818.

9. Bakker EG, Traw MB, Toomajian C, Kreitman M, Bergelson J: Low levels of polymorphism in genes that control the activation of defense response in Arabidopsis thaliana. Genetics 2008, 178(4):2031-2043.
10. Rose LE, Grzeskowiak L, Horger AC, Groth M, Stephan W: Targets of selection in a disease resistance network in wild tomatoes. Mol Plant Pathol 2011, 12(9):921-927.

11. Belkhadir Y, Nimchuk Z, Hubert DA, Mackey D, Dangl JL: Arabidopsis RIN4 negatively regulates disease resistance mediated by RPS2 and RPM1 downstream or independent of the NDR1 signal modulator and is not required for the virulence functions of bacterial type III effectors AvrRpt2 or AvrRpm1. Plant Cell 2004, 16(10):2822-2835.

12. Mackey D, Holt BF, Wiig A, Dangl JL: RIN4 interacts with Pseudomonas syringae type III effector molecules and is required for RPM1-mediated resistance in Arabidopsis. Cell 2002, 108(6):743-754.

13. Pay A, Resch K, Frohnmeyer H, Fejes E, Nagy F, Nick P: Plant RanGAPs are localized at the nuclear envelope in interphase and associated with microtubules in mitotic cells. Plant J 2002, 30(6):699-709.

14. Rose A, Meier I: A domain unique to plant RanGAP is responsible for its targeting to the plant nuclear rim. Proc Natl Acad Sci USA 2001, 98(26):15377-15382.

15. Zhao Q, Brkljacic J, Meier I: Two distinct interacting classes of nuclear envelope-associated coiled-coil proteins are required for the tissuespecific nuclear envelope targeting of Arabidopsis RanGAP. Plant Cell 2008, 20(6):1639-1651.

16. Sacco MA, Mansoor S, Moffett P: A RanGAP protein physically interacts with the NB-LRR protein $\mathrm{Rx}$, and is required for Rx-mediated viral resistance. Plant J 2007, 52(1):82-93.

17. van der Vossen EAG, van der Voort J, Kanyuka K, Bendahmane A, Sandbrink H, Baulcombe DC, Bakker J, Stiekema WJ, Klein-Lankhorst RM: Homologues of a single resistance-gene cluster in potato confer resistance to distinct pathogens: a virus and a nematode. Plant J 2000, 23(5):567-576.

18. Rouppe van der Voort J, Wolters P, Folkertsma RT, Hutten R, Zandvoort P, Vinke $H$, Kanyuka K, Bendahmane A, Jacobsen E, Janssen R, et al: Mapping of the cyst nematode resistance locus Gpa2 in potato using a strategy based on comigrating AFLP markers. Theor App/ Genet 1997, 95(5/6):874-880.

19. Sacco MA, Koropacka K, Grenier E, Jaubert MJ, Blanchard A, Goverse A, Smant G, Moffett P: The cyst nematode SPRYSEC protein RBP-1 elicits Gpa2- and RanGAP2-dependent plant cell death. PLoS Pathog 2009, 5(8):e1000564

20. Carpentier J, Esquibet M, Fouville D, Manzanares-Dauleux MJ, Kerlan MC, Grenier $\mathrm{E}$ : The evolution of the Gp-Rbp-1 gene in Globodera pallida includes multiple selective replacements. Mol Plant Pathol 2012, 13(6):546-555.

21. Mucyn TS, Clemente A, Andriotis VME, Balmuth AL, Oldroyd GED, Staskawicz BJ, Rathjen JP: The tomato NBARC-LRR protein Prf interacts with Pto kinase in vivo to regulate specific plant immunity. Plant Cell 2006, 18(10):2792-2806.

22. Tameling WIL, Nooijen C, Ludwig N, Boter M, Slootweg E, Goverse A, Shirasu K, Joosten M: RanGAP2 Mediates nucleocytoplasmic partitioning of the NB-LRR immune receptor $\mathrm{Rx}$ in the solanaceae. Thereby dictating Rx function. Plant Cell 2010, 22(12):4176-4194.

23. Butterbach $P$, Slootweg E, Koropacka K, Prins P, Roosien J, Spiridon L, Petrescu A, Smant G, Bakker E, Bakker J, et al: Functional constraints and evolutionary dynamics of the Rx1/Gpa2 cluster in potato. In Biology of plant-microbe interactions, Volume 6 Proceedings of the 13th International Congress on Molecular Plant-Microbe Interactions, Sorrento, Italy, 21-27 July 2007. USA: IS-MPMI; 2008:82.

24. Cox BA, Jones RAC: Genetic variability in the coat protein gene of Potato virus $X$ and the current relationship between phylogenetic placement and resistance groupings. Arch Virol 2010, 155(8):1349-1356.

25. Matsubayashi M: Phylogenetic relationships in the potato and its related species. In Chromosome engineering in plants: genetics, breeding, evolution Part B. Elsevier Science; 1991:93-118.

26. Lewontin RC: The interaction of selection and linkage. II. Optimum models. Genetics 1964, 50:757-782.

27. Lewontin RC: The interaction of selection and linkage. I. General considerations; heterotic models. Genetics 1964, 49(1):49-67.

28. Rodriguez F, Spooner DM: Nitrate reductase phylogeny of potato (solanum sect. Petota) genomes with emphasis on the origins of the polyploid species. Syst Bot 2009, 34(1):207-219.

29. Castillo R, Spooner D: Plylogenetic relationships of wild potatoes, solanum series conicibaccata (sect. Petota). PSystematic Botany 1997, 22(1):45-83.

30. Jacobs MMJ, Smulders MJM, van den Berg RG, Vosman B: What's In a name; genetic structure in solanum section petota studied using population-genetic tools. BMC Evol Biol 2011, 11:42. 
31. Jacobs MMJ, van den Berg RG, Vleeshouwers VGAA, Visser M, Mank R, Sengers M, Hoekstra R, Vosman B: AFLP analysis reveals a lack of phylogenetic structure within Solanum section Petota. BMC Evol Biol 2008, 8:145

32. Spooner DM, Castillo R: Reexamination of series relationships of South American wild potatoes (Solanaceae: Solanum sect Petota): Evidence from chloroplast DNA restriction site variation. Am J Bot 1997, 84(5):671-685

33. Goldman N, Yang Z: A codon-based model of nucleotide substitution for protein-coding DNA sequences. Mol Biol Evol 1994, 11(5):725-736.

34. Kimura M: Preponderance of synonymous changes as evidence for the neutral theory of molecular evolution. Nature 1977, 267(5608):275-276.

35. Muse SV, Gaut BS: A likelihood approach for comparing synonymous and nonsynonymous nucleotide substitution rates, with application to the chloroplast genome. Mol Biol Evol 1994, 11(5):715-724.

36. Cavatorta JR, Savage AE, Yeam I, Gray SM, Jahn MM: Positive darwinian selection at single amino acid sites conferring plant virus resistance. $\mathrm{J}$ Mol Evol 2008, 67(5):551-559.

37. Hofinger BJ, Russell JR, Bass CG, Baldwin T, Dos Reis M, Hedley PE, Li YD, Macaulay M, Waugh R, Hammond-Kosack KE, et al: An exceptionally high nucleotide and haplotype diversity and a signature of positive selection for the eIF4E resistance gene in barley are revealed by allele mining and phylogenetic analyses of natural populations. Mol Ecol 2011 20(17):3653-3668.

38. Rehman S, Postma W, Tytgat T, Prins P, Qin L, Overmars H, Vossen J, Spiridon LN, Petrescu AJ, Goverse A, et al: A secreted SPRY domaincontaining protein (SPRYSEC) from the plant-parasitic nematode globodera rostochiensis interacts with a CC-NB-LRR protein from a susceptible tomato. Mol Plant Microbe Interact 2009, 22(3):330-340.

39. Gutierrez JR, Balmuth AL, Ntoukakis V, Mucyn TS, Gimenez-Ibanez S, Jones AME, Rathjen JP: Prf immune complexes of tomato are oligomeric and contain multiple Pto-like kinases that diversify effector recognition. Plant J 2010, 61(3):507-518.

40. Mucyn TS, Wu A-J, Balmuth AL, Arasteh JM, Rathjen JP: Regulation of tomato Prf by Pto-like protein kinases. Mol Plant Microbe Interact 2009, 22(4):391-401.

41. Meyers BC, Shen KA, Rohani P, Gaut BS, Michelmore RW: Receptor-like genes in the major resistance locus of lettuce are subject to divergent selection. Plant Cell 1998, 10(11):1833-1846.

42. Farnham G, Baulcombe DC: Artificial evolution extends the spectrum of viruses that are targeted by a disease-resistance gene from potato. Proc Natl Acad Sci USA 2006, 103(49):18828-18833.

43. Kavanagh T, Goulden M, Santa Cruz S, Chapman S, Barker I, Baulcombe D: Molecular analysis of a resistance-breaking strain of potato virus $\mathrm{X}$. Virology 1992, 189(2):609-617.

44. Bittner-Eddy PD, Crute IR, Holub EB, Beynon JL: RPP13 is a simple locus in Arabidopsis thaliana for alleles that specify downy mildew resistance to different avirulence determinants in Peronospora parasitica. Plant J 2000, 21(2):177-188.

45. Banerjee D, Zhang XC, Bent AF: The leucine-rich repeat domain can determine effective interaction between RPS2 and other host factors in Arabidopsis RPS2-mediated disease resistance. Genetics 2001, 158(1):439-450.

46. Tameling WIL, Baulcombe DC: Physical association of the NB-LRR resistance protein $\mathrm{Rx}$ with a ran GTPase-activating protein is required for extreme resistance to Potato virus X. Plant Cell 2007, 19(5):1682-1694.

47. Rooney HCE, Klooster JW, Hoorn RAL, Joosten MHAJ, Jones JDG, Wit PJGM: Cladosporium Avr2 inhibits tomato Rcr3 protease required for $\mathrm{Cf}-2$ dependent disease resistance. Science (Washington) 2005, 308(5729):1783-1786.

48. Lozano-Torres JL, Wilbers RHP, Gawronski P, Boshoven JC, Finkers-Tomczak A, Cordewener JHG, America AHP, Overmars HA, t Klooster JW, Baranowski $\mathrm{L}$, et al: Dual disease resistance mediated by the immune receptor $\mathrm{Cf}-2$ in tomato requires a common virulence target of a fungus and a nematode. Proc Natl Acad Sci USA 2012, 109(25):10119-10124.

49. Fulton T, Chunwongse J, Tanksley S: Microprep protocol for extraction of DNA from tomato and other herbaceous plants. Plant Mol Biol Rep 1995, 13(3):207-209.

50. Hall TA: BioEdit: a user-friendly biological sequence alignment editor and analysis program for Windows 95/98/NT. Nucl Acids Symp Ser 1999 41:95-98.
51. Tamura K, Peterson D, Peterson N, Stecher G, Nei M, Kumar S: MEGA5: molecular evolutionary genetics analysis using maximum likelihood, evolutionary distance, and maximum parsimony methods. Mol Biol Evol 2011, 28(10):2731-2739.

52. Tamura K: Estimation of the number of nucleotide substitutions when there are strong transition-transversion and $\mathrm{G}+\mathrm{C}$-content biases. $\mathrm{Mol}$ Biol Evol 1992, 9(4):678-687.

53. Schultz J, Milpetz F, Bork P, Ponting CP: SMART, a simple modular architecture research tool: identification of signaling domains. Proc Natl Acad Sci USA 1998, 95(11):5857-5864.

54. Librado P, Rozas J: DnaSP v5: a software for comprehensive analysis of DNA polymorphism data. Bioinformatics 2009, 25(11):1451-1452.

55. Yang Z: PAML: a program package for phylogenetic analysis by maximum likelihood. Comput Appl Biosci 1997, 13(5):555-556.

56. Kosakovsky Pond SL, Frost SD: Not so different after all: a comparison of methods for detecting amino acid sites under selection. Mol Biol Evol 2005, 22(5):1208-1222.

57. Delport W, Poon AF, Frost SD, Kosakovsky Pond SL: Datamonkey 2010: a suite of phylogenetic analysis tools for evolutionary biology. Bioinformatics 2010, 26(19):2455-2457.

58. Excoffier L, Laval G, Schneider S: Arlequin (version 3.0): an integrated software package for population genetics data analysis. Evol Bioinform Online 2005, 1:47-50

59. Bendahmane A, Kanyuka K, Baulcombe DC: The Rx gene from potato controls separate virus resistance and cell death responses. Plant Cell 1999, 11(5):781-791.

doi:10.1186/1471-2148-13-87

Cite this article as: Carpentier et al:: Evolution and variability of Solanum RanGAP2, a cofactor in the incompatible interaction between the resistance protein GPA2 and the Globodera pallida effector Gp-RBP-1. BMC Evolutionary Biology 2013 13:87

\section{Submit your next manuscript to BioMed Central and take full advantage of:}

- Convenient online submission

- Thorough peer review

- No space constraints or color figure charges

- Immediate publication on acceptance

- Inclusion in PubMed, CAS, Scopus and Google Scholar

- Research which is freely available for redistribution 